\title{
A ECONOMIA SOLIDÁRIA NO CURRÍCULO DA EJA: DESAFIOS E PERSPECTIVAS PARA A FORMAÇÃO DO DOCENTE
}

\author{
Simary Muniz de Oliveira, Instituto Federal da Paraíba (IFPB), \\ simary-oliveira@hotmail.com
}

Mayara Muniz de Oliveira, Universidade Estadual do Rio Grande do Norte (UERN), mayaramunizoliveira@gmail.com

Vorster Queiroga Alves, Universidade Federal de Campina Grande (UFCG), vorster.queiroga@gmail.com

\begin{abstract}
RESUMO
O objetivo dessa pesquisa foi analisar como o currículo da EJA pode ser um instrumento de formação continua para docentes que atuam na EJA. Foi realizado um estudo de campo, sendo utilizada a entrevista para coletar dados junto as instituições pesquisadas, que foram três escolas da rede pública sendo (01) municipal e (02) estaduais que atendem aos alunos da EJA do Ensino Fundamental e Médio e a visita a Presidenta da Cooperativa de empreendimentos solidários na cidade de Pombal/PB. Os resultados indicam uma expectativa positiva por uma visão melhor de mundo, adquirir conhecimento intelectual e através de sua aprendizagem os mesmos podem ter a sua libertação, seja econômica, social ou mesmo modificar a realidade na qual está inserido. Os cooperados viram que a Economia Solidária pode ser um meio de melhoria de vida, mas que só através do conhecimento e entendimento do que seria empreendimento solidaria seria mais fácil conscientizar mais cooperados e poderem aos poucos libertarem um grande número de sujeitos do capitalismo que fazem dos mesmos verdadeiros escravos da economia social.
\end{abstract}

PALAVRAS - CHAVE: EJA, Currículo; Economia Solidária; Formação do Docente.

\section{THE SOLIDARITY ECONOMY IN THE CURRICULUM OF THE EJA: CHALLENGES AND PROSPECTS FOR TEACHER TRAINING}

\begin{abstract}
The objective of this research was to analyze how the EJA curriculum can be an instrument of continuous training of teachers works in EJA. It made use of a field study; an interview to collecting data from the researched institutions, three public school: (01) municipal and (02) state schools that attend the EJA's students of Elementary and Middle School; and one visit of the President of the Cooperative of New development in Pombal,PB, one border city. The results indicate a positive expectation for a better view of the World, to acquire intellectual knowledge and how the students, through their knowledg, can get their libertation economic or social, even modify the reality in which they're inserted. The cooperatives realized that the Solidarity Economy could be a way of improving life, but just through knowing and understanding what would be the New development would been easier to raise awareness
\end{abstract}

Revista de Pesquisa Interdisciplinar, Cajazeiras, n. 2, suplementar, p. 378-392, set. de 2017. 
among cooperatives and to gradually liberate a large number of subjects from capitalism that make it slaves of the social economy.

KEYWORDS: EJA, Curriculum, Solidary Economy, Teacher Training.

\title{
LA ECONOMÍA SOLIDARIA EN EL CURRÍCULO DE LA EJA: DESAFÍOS Y PERSPECTIVAS PARA LA FORMACIÓN DEL DOCENTE
}

\begin{abstract}
RESUMEN
El objetivo de esta investigación fue analizar cómo el currículo de la EJA puede ser un instrumento de formación continua para docentes que actúan en la EJA. Se realizó un estudio de campo, siendo utilizada la entrevista como la forma de recolectar datos junto a las instituciones investigadas, que fueron tres escuelas de la red pública siendo (01) municipal y (02) estaduales que atienden a los alumnos de la EJA de la Enseñanza Fundamental y Medio Y la visita a la Presidenta de la Cooperativa de emprendimientos solidarios en la ciudad de Pombal / PB. Los resultados indican una expectativa positiva por una visión mejor del mundo, adquirir conocimiento intelectual ya través de su aprendizaje los mismos pueden tener su liberación, ya sea económica, social o incluso modificar la realidad en la que está inserto. Y que los cooperados vieron que la Economía Solidaria puede ser un medio de mejora de vida, pero que sólo a través del conocimiento y entendimiento de lo que sería emprendimiento solidario sería más fácil concientizar más cooperados y poder poco a poco liberar a un gran número de sujetos del capitalismo que, Hacen de los mismos verdaderos esclavos de la economía social.
\end{abstract}

PALABRAS CLAVES: EJA, Currículo, Economía Solidaria, Formación del Docente. INTRODUÇÃO

Buscar proporcionar uma visão comparativa no modo em que a economia solidária trabalha no currículo da EJA constitui um pressuposto para a formação continuada dos docentes da EJA. Com as diversidades e as mudanças sociais e até mesmo econômicas levaram a busca por novas alternativas para que pudessem despertar nesses sujeitos o seu próprio desenvolvimento. Analisamos que os retornos destes sujeitos às salas de aula estejam ligados há vários fatores de diferentes naturezas, das quais podemos destacar as seguintes razões como: sociais, culturais, políticas, econômicas e até mesmo pedagógicas, voltados para uma democratização da educação visando melhorias na qualificação dos trabalhadores. 
Autores como Freire (2006) e Gadotti (2006) destacam que dentre as consequências desses fatores, a reformulação do currículo da EJA, voltado à realidade do educando que busca nesta modalidade de ensino uma alternativa de emancipação de vida, seja ela profissional ou social.

A sociedade brasileira verá ao longo de sua história um grande número de analfabetos, interferindo direto ou indiretamente na sua democratização e na preparação do trabalhador. Quando o sujeito visar que dentro dos empreendimentos solidários pode haver um meio de melhoria de sua vida ela poderá associar a EJA, ou seja, seus conhecimentos já adquiridos em sala de aula junto a Economia Solidária e ser capaz de modificar seu meio.

Ainda com foco nos professores da EJA, faz-se necessário perceber se de fato acreditam na capacidade e no desenvolvimento intelectual dos seus educandos. A determinação desses objetivos decorreu devido à relevância do tema, tendo em vista de conhecer melhor o currículo da EJA e seus desafios na tentativa de entender melhor os seus anseios e buscar meios e alternativas que possam modificar de forma significativa a vida destes educandos visando uma forma em que cada um que busca na EJA como meio para sua emancipação de vida e atrelando a educação juntamente à Economia Solidária podemos ver um meio para que isso possa acontecer.

O objetivo do trabalho consiste em analisar como o currículo da EJA pode ser um instrumento de formação continua para docentes que atuam na EJA.

Esse estudo buscou contribuir e ampliar os aspectos teóricos e metodológicos sobre o referido tema, o qual é relativamente novo; pouco explorado e pesquisado. Para tanto, o método utilizado para o trabalho foi-se a categorização dos formulários de entrevistas por meio da gravação do áudio.

\section{MATERIAIS E MÉTODOS}

A forma de abordagem foi por meio da pesquisa qualitativa, com método de pesquisa de campo. A técnica usada é o formulário de entrevista com a gravação de áudio e transcrição posterior das gravações, para análise. Quanto ao nível de pesquisa, é exploratória, pois remete uma visão global dos fatos estudados. 
As instituições que escolhidas para a pesquisa foram três escolas da rede pública, sendo (01) municipal e (02) estaduais que atendem aos alunos da EJA do Ensino Fundamental e Médio na cidade de Pombal - PB. Os dados coletados foram em abril de 2013, por meio de formulários de entrevista direcionados a 10 professores desta modalidade de ensino, sendo por acessibilidade e visando uma maior forma de coleta de informações precisas.

Também foi utilizado o método da observação para facilitar a compreensão dos dados obtidos, pois pode ser empregado para comparações de grupo, sendo assim, estudaram-se as semelhanças e diferenças.

\section{RESULTADOS E DISCUSSÃO}

O texto é apresentado em dois momentos distintos: o primeiro apresenta momentos históricos da EJA no Brasil e a formação do docente no EJA, baseado nos estudos de autores como; Freire (2005), trazendo uma discursão dos fatos históricos mais relevantes de cada época. O segundo aborda: O currículo da EJA de acordo com alguns autores como Moura (1999) e Singer (2005) para obter conhecimento do perfil do currículo que está sendo trabalhado nas salas de aula da EJA, o segundo momento aborda ainda: As possibilidades do currículo da EJA a Economia Solidária, buscando trazer informações voltadas para a realidade que cada educando está inserido.

\section{EJA: CRESCIMENTO E MELHORIAS}

Com o crescimento da EJA foram criando vários projetos de lei e o desenvolvimento de programas educacionais voltados à necessidade da classe social desses trabalhadores que está se formando em nosso país. Nas falas dos Professores podemos perceber a ressalva que o Professor 02 faz sobre a inclusão do educando da EJA: "Repararia a escola para agir como suporte de inclusão e aperfeiçoamento para o mercado de trabalho, além de dar subsídios para se inserir na universidade". Com base nas palavras do professore podemos ver que a modalidade de EJA pode sim trabalhar seus conteúdos voltados à realidade dos quais eles fazem parte. 
Com isso foi se implantado a lei da LDB (Lei de Diretrizes e Bases da Educação) 5692/71 que criava uma nova modalidade de ensino que era denominado de supletivo com esta nova lei ela atendia as necessidades especificamente para os educandos da EJA.

A partir de 1974, o MEC começou a ampliar os CES (Centros de Estudos Supletivos), os centros tinham influências, tecnicistas devido à situação política que o país vivia naquele momento. Com isso foram criadas iniciativas em favor da educação de Jovens e Adultos, o governo incluiu estados, municípios, centros universitários, grupos informais, ONG'S com o intuito de começar a registrar a história do avanço da EJA.

Nesta fase a história da educação brasileira, a EJA, procura promover uma sociedade igualitária e uma educação renovadora capaz de atender as necessidades de todas as áreas de conhecimento procurando focar e valorizar o conhecimento prévio do educando que já tinha antes de chegar à sala de aula era o chamado conhecimento de mundo visando dessa forma procurava favorecer uma troca de conhecimentos entre educando e educador. Percebe-se na fala do entrevistado a perspectiva que o Professor 07 faz em suas palavras: "Vejo que os alunos que fazem parte da EJA têm muito conhecimento de mundo e com isso se torna mais fácil o desenvolvimento de cada um".

\section{PAULO FREIRE E A EDUCAÇÃO DE JOVENS E ADULTOS}

Paulo Freire marcou a história da Educação de Jovens e Adultos com a sua criação de novas práticas pedagógicas e métodos inovadores que tinha na área da educação procurou da ênfase a uma classe social desfavorecida de conhecimentos como também socioeconômica.

Percebe-se que o autor faz uma ruptura nos paradigmas formais que constituíam a educação brasileira ele procurou valorizar o que o educando já sabia, ou seja, valorizar seu conhecimento prévio de mundo e até mesmo de experiência de vida. Sabe-se que Freire jamais deixou de lutar pela a superação da opressão e das desigualdades sociais entendendo que para o sujeito conseguir superar seus obstáculos seria através da educação e foi nesta perspectiva que ele desenvolveu práticas voltadas para atender às necessidades destes sujeitos fazendo com eles fossem capazes de superar suas dificuldades.

Para Paulo Freire o ato educativo deve ser sempre um ato de recriação, de resignificação de significados. Segundo Freire o mesmo buscava alternativas capazes de fazer 
uma alfabetização visando a libertação do sujeito de forma essencial na vida social, socioeconômica, educativa e política do educando, mas para atender esse processo precisamos ter educadores capazes de fazer despertar esse desenvolvimento intelectual em cada educando que está inserido na Educação de Jovens e Adultos. Vejamos o descontentamento com atual situação do currículo da EJA nas palavras do Professor 06: "Se tivéssemos disciplinas voltadas à realidade dos educandos seria mais fácil trabalhar a dificuldade de cada um". Assim Freire defende uma renovação na educação no Brasil que fosse capaz de promover a emancipação intelectual do sujeito.

Segundo o autor a educação só poderia proporcionar no indivíduo um processo de mudança de conscientização do mesmo, onde ele fosse capaz de ser formador de sua própria opinião. A respeito disso o Professor $07 \mathrm{diz}$ que "Os professores deveriam ser mais audaciosos em sala de aula eles mesmos poderem modificar seu conteúdo de acordo com a realidade de sua turma sendo assim aconteceria mais rápido o desenvolvimento e aprendizagem de cada aluno".

Com o desenvolvimento mais rápido do educando seria uma maneira mais fácil de mostrar que o sujeito era capaz de promover a sua própria formação de conhecimentos através da educação.

\section{A ATUAÇÃO DO DOCENTE NA EJA}

A formação de professores para o curso de EJA, ainda não é uma prioridade no currículo de formação acadêmica. Com essa falta de formação continuada onde podemos notar um grande despreparo por parte de alguns profissionais que atuam na Educação de Jovens e Adultos, e com essa falta de formação o currículo proposto pela a modalidade de ensino/aprendizagem onde começa nas maiorias das salas de aula da EJA uma defasagem no seu currículo onde seus métodos e formas de melhorias no ambiente escolar passam a ser modificada. Segundo o entrevistado o Professor 05 ele relata " $O$ modo de vida que o indivíduo tem que favorece o cooperativismo valoriza a produção, a compra de produtos sem explorar o próximo, sua ideologia enfatiza a relação econômica e social voltada para o bem comum".

Não é como um educando que frequenta o ensino regular é uma pessoa que requer mais atenção do seu orientador não só por parte de transmissão e de conhecimentos. 
Completando essa ideia com suas palavras o Professor 06 ressalvas que: "Vejo que uma das maiores dificuldades que enfrentamos junto à Educação de Jovens e Adultos é falta de recursos didáticos voltados à realidade de cada sujeito que está inserido".

O educador da EJA precisa fazer um conhecimento prévio de seu educando, para poder saber identificar seu potencial no ensino aprendizagem e suas dificuldades. Como o Professor 06 ressalta em suas palavras: "Através do conhecimento adquirido de cada aluno que está na EJA ou num serie regular é de extrema importância para sua vida profissional e pessoa". Através dos conhecimentos adquiridos na sala de aula pode despertar no educando uma forma inovadora de poder transformar sua vida através da educação que modificar o seu meio. Para evitar que desperte no mesmo a acomodação e oferecer um curso de qualidade que ele tenha motivação de promover em seus educandos um crescimento pessoal e profissional e que forme cidadãos capazes de serem formadores de opiniões e conhecimento, lembrando que só educação de mudança quando se faz sentido significativo na vida do educando.

Vários autores como Lopes (2013), Hoffmann (2004) e outros discutem o que é preciso que os educadores que atuam no ensino da EJA sejam e estejam capacitados para atuarem em suas salas de aulas. Para que a aprendizagem aconteça de forma contínua nas salas de aula da EJA é preciso uma nova construção de sentidos valorizando o conhecimento do educando, pois, o saber vem de todos os lugares de diversos tipos de sujeitos.

O educador da EJA precisa não ser só diferente na transmissão dos conteúdos didáticos como também saber estimular e elevar a autoestima, procurando despertar em seus educandos a sua própria valorização mostrando ao o mesmo que é capaz de fazer a sua própria construção de conhecimentos. Em relação ao assunto Hoffmann faz à seguinte ideia "O papel do avaliador, ativo em termos do processo, transforma-se no de partícipe do sucesso ou fracasso dos alunos, uma vez que os percursos individuais serão mais ou menos favorecidos a partir de suas decisões pedagógicas que dependerão, igualmente, da amplitude das observações" (HOFFMANN, 2004, p.18).

O Professor 03 menciona em suas palavras a importância de alternativas voltadas a realidades dos educandos como: "É uma boa forma de ensinarmos uma alternativa de geração de trabalho e renda, voltada para a inclusão social". Como bem ressalva o Professor 03 em suas palavras vemos na educação meios de obter uma forma de melhorar a inclusão social dos mesmos. E com esta visão renovadora do o conhecimento e da realidade em que cada um está 
inserido que o educador vai poder desenvolver seu papel não só de educador, mas como um orientador que saiba transmitir conhecimentos pedagógicos e valores éticos, morais e sociais a cada educando que está ali em sua sala de aula.

A aprendizagem não pode ser simplesmente transmitida, ela é um processo de construção ao longo de um determinado período escolar onde o educador busca oferecer meios que favoreçam a construção do saber, a do conhecimento: tudo o que já foi vivido pelo educando antes de chegar à escola como base, o educador deve utilizar também a vivência e o conhecimento prévio do educando para facilitar na construção do saber. O Professor 01 destaca em suas palavras que: "Os conteúdos deveriam ser de acordo com a capacidade e a realidade dos alunos". Aquilo que é oferecido ao alfabetizando deve fazer sentido para ele, se o educador partir de um ponto desconhecido que foge à realidade do mesmo ele poderá não alcançar a compreensão necessária ao seu desenvolvimento intelectual diante disso cabe ao educador ser flexível, dinâmico e principalmente audacioso para ser capaz de modificar essa realidade.

\section{O CURRÍCULO DA EJA EM CONSTRUÇÃO PERMANENTE}

Esse item tem como objetivo fazer uma análise da proposta pedagógica curricular que é oferecida nas salas de aula da EJA, procurando rever as habilidades que são oferecidas nesta modalidade de ensino, onde se busca garantir aos educandos uma educação básica de qualidade, dando uma ênfase nos seus conhecimentos de tempo e de mundo. Por isso é que a EJA deve ser vista e analisada como um processo de formação continuada, e até mesmo contínua, onde se dá um processo de formação através de seus conhecimentos já adquiridos antes de chegarem à sala de aula, onde se devem levar em conta suas experiências de vida, procurando revelar o seu trabalho e a própria vivência dos Jovens e Adultos que são os principais destinatários dessa modalidade de ensino e educação.

A EJA visa ser à construção de uma nova sociedade que possa valorizar o sujeito e sua capacidade de produção de vida, buscando assegurar os seus direitos sociais e que cada um possa ter conhecimento para que possa reivindicar de forma correta. Completando essa ideia Freire faz uma ressalva de: "Estar no mundo implica necessariamente estar com o mundo e com os outros" (FREIRE, 2005, p. 20). E é nesta visão que a educação da EJA busca ao logo de sua existência ser entendida e vista como um conjunto de processos de ensino 
aprendizagem que possibilitem aos Jovens e Adultos o seu desenvolvimento de suas capacidades intelectuais e o enriquecimento dos conhecimentos técnicos e profissionais. É de fundamental importância ver na EJA, como uma maneira de resgatar as ações dos Jovens e Adultos, intensificando os seus conhecimentos prévios e ampliando sua consciência como até mesmo a sua existência humana.

Com a visão de renovação da educação brasileira onde exige uma ruptura, em sua desestruturação e restruturação não só nos modos de pensar, mas em todos os métodos que estão sendo aplicados para a construção de uma educação capaz de estruturar o sujeito que faz parte dela. Compreendendo que há uma necessidade de uma renovação de uma pratica pedagógica diferenciada na EJA. Segundo Moura, diz que: "ao selecionar criteriosamente, dentre todos os conhecimentos desenvolvidos, aqueles relevantes para a iniciação dos jovens no mundo social. Ao mesmo tempo, exerce seu papel transformador ao preparar criticamente os jovens, capacitando-os a analisar sua sociedade [...] (MOURA, 1999, p. 97). E nesta partilha em que o autor faz suas observações podemos ver que a Educação de Jovens e Adultos ela capaz de transformar o seu meio em se vive como também modificar cada sujeito que faz parte dela, buscando novas formas de valorizar suas capacidades.

\section{AS POSSIBILIDADES DO CURRÍCULO DA EJA ALIANDO-SE COM A ECONOMIA SOLIDARIA}

Com base na avaliação do currículo que é oferecido na Educação de Jovens e Adultos pede que sejam analisados alguns pontos fundamentais no tocante a relação no que diz respeito ao seu processo de criação, seleção, organização e até mesmo a distribuição do conhecimento escolar os processos sociais são distribuídos de acordo com seus diferentes grupos sociais; onde os elementos ideológicos como: o conformismo, produção de pensamentos críticos faça com o sujeito seja capaz de formar seus pensamentos. Como bem faz uso de sua opinião o entrevistado o Professor 06 ressalvas: "As iniciativas deveriam ser colocadas em pratica de imediato seria uma reformulação na grade curricular que oferecida na modalidade da EJA". Com a reformulação e renovação do currículo se adequando a realidade dos mesmos fazendo com que seu ensino seja motivador e prazeroso que seus conteúdos sejam voltados a sua realidade no seu trabalho despertando neles uma alternativa de poder haver uma emancipação no seu trabalho e até mesmo na vida. A esse respeito, Freire (1997) 
comenta que a transformação social é feita de muitas tarefas e que ele estava incumbido de pôr em prática o discurso.

Nesta perspectiva que a resistência presente no currículo da EJA, dentre outros, uma análise puramente pedagógica e metodológica possibilita numa reconstrução de um novo currículo voltado ao crescimento e desenvolvimento contínuo dos educandos. No entanto o entrevistado o Professor 04 define em suas palavras que o currículo da EJA: "Deveria oferecer disciplinas práticas que proporcionassem experiência para qualificá-lo melhor”. Com essa visão uma intensa mobilização dos segmentos escolares, dos poderes públicos, da sociedade civil e até mesmo da classe escolar onde, pode-se conquistar na história da educação brasileira a construção cotidiana de um novo currículo da EJA, onde seja construída num espaço de reflexão, expressão, humanização, articulação e o diálogo entre as partilhas de saberes populares e o científico.

Reorganizar um novo currículo para a Educação de Jovens e Adultos implica na construção de um novo processo que se realiza entre lutas, conflitos de posições entre a relação de poder. Ao introduzirmos os princípios da Economia Solidária em pauta nos planos escolares e nas salas de aula de EJA, educandos e educadores e os gestores são convidados a refletirem sobre a diversidade sócio/cultural que permeia a EJA, pois, educar é uma nova forma de criar novas possibilidades de ensino/aprendizagem nas quais todos os sujeitos envolvidos tenham a possibilidade de despertar para a sua dignidade de sujeitos capazes de modificar seu futuro. Segundo Freire (2001) é possível ter uma educação capaz de modificar o ser humano, pois torna-se possível a vida sem sonho, mas não a existências humana e história sem sonho.

Sendo assim, com a modificação do currículo da EJA ele é capaz de fazer um resgate do saber local onde o sujeito esteja inserido junto com a sua prática real unindo esses dois paradigmas vemos uma nova forma de construção de novos saberes dentro do ambiente escolar e nas salas de aula. Dentre muitas situações didáticas que procuram se aprofundarem neste assunto, os temas geradores passam a levantar inúmeras discussões de diversas formas temáticas que envolvem questões de vivencias diárias dos educandos da EJA como as questões de saúde, segurança, ética, direitos humanos, educação, serviços públicos entre outros. 
Segundo o entrevistado o Professor 05 destaca que: "É essencial porque humaniza o indivíduo, ensina a defender o cooperativismo e valorizar o trabalho em grupo". A Economia Solidária seria um meio onde os sujeitos dos quais fizessem parte dela pudessem conseguir seu desenvolvimento econômico acontecer onde os mesmos desenvolvessem alternativas dentro do empreendimento solidário alternativas para sua emancipação de vida, sem precisarem de programas sociais.

$\mathrm{Na}$ visão de Paulo Singer a Economia Solidária é entendida como uma estratégia de luta e sobrevivência dos movimentos populares contra as desigualdades sociais, e até mesmo da exclusão social.

O desenvolvimento da Economia Solidária, no meio do capitalismo não tem nada de natural, pelo contrário exige dos sujeitos que fazem parte dela um comportamento social diferenciado pautado pela forma da solidariedade da humanização entre os sujeitos que estão inseridos e não visa mais a competição, a disputa entre o poder, espaço econômicos e sociais (SINGER, 2002). Segundo Andrioli (2001) o desenvolvimento solidário é capaz de modificar uma sociedade como ressalva em suas palavras.

Fica bem claro que colocado em prática a Economia Solidária passa a exigir dos sujeitos que se formaram no capitalismo e tem o espírito competitivo e capitalista sejam reeducados. É uma formação com resultados ao longo dos anos de luta dos oprimidos desenvolvida pela solidariedade, pela a cooperação, pela autogestão, procurando valorizar a potencialidade de cada integrante que faz parte da Economia Solidária, onde se haja interrupção nos paradigmas e sejam superados. Os grupos solidários precisam do envolvimento e participação de cada sujeito cooperado, exercendo o seu exercício de democracia e de cidadania; construção do novo através de forma coletiva e solidária respeitando os limites de cada sujeito.

Moll (2004) nos faz refletir sobre a Educação Popular onde a mesma não é feita somente através de livros e conhecimentos científicos, e que ela representa um meio de educação no qual o sujeito que faz parte os seus conhecimentos sejam vistos como uma forma de saber popular da qual a mesma pode ser uma grande aliada da EJA e da Economia Solidária. 


\section{EJA E ECOSOL UM DIÁLOGO NA FORMAÇÃO DOS EDUCADORES DA EJA}

A educação procura promover nos seus sujeitos que fazem parte dela, a construção da consciência voltada as suas melhorias de vida, visando também à melhoria na qualidade do ensino, à melhoria das relações interpessoais que se travam dentro do ambiente escolar, buscando uma melhorar em seu trabalho, dentre outros fatores o educando possa reivindicar.

Os educadores no qual atua na Educação de Jovens e Adultos precisam engajar-se socialmente e politicamente, percebendo as possibilidades da ação social e cultural pela a transformação das estruturas existentes na sociedade capitalista, travando assim uma disputa desleal, entre o opressor e o oprimido, onde esta disputa na maioria das vezes sempre é o oprimido que sai perdendo. Cabe ao educador ver que o mesmo tem esse poder de modificar seu educando e seu meio do qual está inserido através do conhecimento o sujeito pode desenvolver a capacidade de argumentar e interpretar o mundo em que vive quando o seu educador já fez isso a diferença na vida do mesmo já é notória direto ou indiretamente.

Mas a educação em sim e em especial na EJA, procura criar um espírito investigativo coletivo, capaz de envolver todos os sujeitos dos processos de formação, tanto para desenvolvimento do mundo como desenvolver na busca de novos caminhos, favorecendo nas transformações econômicas, políticas, sociais e culturais, como nos faz nortear-se dentro da formação/educação em economia solidária. Para Singer ele define que a Economia Solidária é uma estratégia de luta e de movimentos populares contra a exclusão social.

Quando tratamos do assunto da formação dos educadores da EJA é preciso levar em consideração as questões relacionadas às lutas sociais, pois estas influenciam na fisionomia das lutas pedagógicas. Os princípios da educação popular precisam dialogar com a educação formal, pois este diálogo entre essas esferas nos traz alternativas de libertação ao fazer essa relação dinâmica dos grupos populares com a realidade social do qual estão inseridas e quando essas realidades passam a ser compreendidas por todos os grupos, fica bem mais fácil acontecer uma educação renovadora capaz de modificar os sujeitos que fazem parte dela.

A Educação de Jovens e Adultos pensada de forma diversificada procurando valorizar e envolver os educandos e buscando aprimorar os seus conhecimentos já adquiridos ao longo de suas vidas, defende assim a dimensão humana em todas as suas possibilidades; e ao procurar resgatar esses valores e práticas estamos fazendo uma educação capaz de trazer a 
solidariedade, a compreensão, o cooperativismo para dentro das salas de aula da EJA, espelhados nos princípios da Economia Solidária, trazemos para a realidade do ambiente escolar uma discussão nos núcleos de alfabetização de que a vivência de outro mundo é possível. Segundo Kruppa (2005), a Economia Solidária pode levar os sujeitos que fazem parte dela a uma igualdade social e até mesmo econômica.

Kruppa (2005) completa ao enfocar os princípios da Economia Solidária nos planos de aula nas salas de Educação de Jovens e Adultos, procuramos levar uma reflexão sobre a diversidade de conhecimentos sócio-cultural que permeia na EJA, pois educar é criar situações de ensino aprendizagem dos quais todos os sujeitos envolvidos possam despertar para a sua dignidade de indivíduos capazes de modificar seu próprio futuro. Sendo assim, um currículo onde a EJA e a Economia Solidária fazem um diálogo é considerado um artigo social e cultural, pois o desenvolvimento da Economia Solidária traz o saber local ou de uma comunidade para a prática real da sala de aula.

A educação popular concebe uma aprendizagem diferenciada voltada ao desenvolvimento de tarefas criativas na qual o desenvolvimento do conhecimento é construído e reconstruído, mas principalmente transformar os sujeitos e fazer neles o poder de desenvolver a capacidade de pensar, sentir, fazer, para que ele possa transformar a sua realidade em que está inserido. E é nesta perspectiva que a educação não pode ser reduzida apenas tentando passar conteúdos científicos, mas que possa envolver a realização de todo processo rico e complexo e que exista condições de desenvolver um sujeito capaz de ser cooperador em prol de modificar o seu meio sócio/cultural.

\section{CONCLUSÕES}

O estudo é resultado de uma pesquisa de campo, onde foi possível investigar professores de diferentes níveis escolares, alunos com diversos tipos de formação e cooperados de empreendimentos solidários, voltados à realidade de cada um. Consequentemente, o objetivo geral desta pesquisa propôs realizar uma análise comparativa das expectativas de alunos professores e cooperados. As opiniões alunos, como professores e cooperados, demonstram com palavras diferentes que a expectativa em ter uma visão melhor de mundo, adquirir conhecimento intelectual e através de sua aprendizagem os mesmos 
podem ter a sua libertação, seja ela econômica, social ou até mesmo modificar a realidade na qual está inserido.

No pensamento dos educandos podemos notar na fala dos entrevistados que os mesmos buscam na EJA como meio de obter conhecimento intelectual, crescimento pessoal, e que através da Economia Solidária, seria uma alternativa de emancipação de vida. Observa-se que na fala da maioria dos professores que os governantes deveriam urgentemente fazer uma reformulação no currículo que é oferecido pela modalidade de ensino da EJA tanto no fundamental e médio. Podemos destacar que a Economia Solidária seria uma alternativa inovadora quando associada à EJA, onde a mesma poderia modificar a vida social e econômica dos mesmos.

Com relação à expectativa dos cooperados, podemos concluir que os mesmos perceberão que a Economia Solidária atrelada ao cooperativismo, à união de todos foi um meio de emancipação de vida social e economia. Podemos ver isso na fala da Cooperada 01 diz que: "acho essa interação, essa união coletiva é a base mestra da cooperativa".

Ao analisarmos os resultados das entrevistas constatamos que dentre os entrevistados, pouquíssimos disseram que buscavam na EJA um meio de mudar de vida e que através da Economia Solidária, juntamente com a educação, poderiam ter uma vida melhor com a obtenção de melhores resultados como um emprego melhor e até mesmo uma mudança de vida econômica para eles e para sua comunidade. A maioria vê a EJA como um caminho para conseguir uma melhor qualificação profissional e com isso possa obter o seu tão almejado sucesso pessoal e profissional.

A educação é vista como um valor que se acredita ter uma ascensão social. Grande parte dos educandos da EJA estão inseridos no mercado de trabalho e não visam apenas à certificação para manter sua situação profissional. Este estudo evidenciou o quanto o conhecimento intelectual é importante na vida dos mesmo que busca na EJA uma emancipação de vida visando não ter só um bom emprego, mas de fato ter um reconhecimento da sociedade diante de seus esforços. Analisamos que a falta de políticas públicas voltadas a essa realidade ainda é escassa, mas cabe aos educadores e os educandos reivindicarem seu espaço diante da sociedade visando ter melhorias, através de programas e ações voltadas para a melhora desta modalidade de ensino seja ela para o profissional que atua na EJA e para os educandos visando construir um currículo voltado e moldado as suas necessidades. Ressalva 
que o currículo oferecido não supre as expectativas que buscam na EJA uma melhoria no seu desenvolvimento intelectual. Concluímos que os cooperados viram que a Economia Solidária pode ser um meio de melhoria de vida, mas que só através do conhecimento e entendimento do que seria empreendimento solidaria seria mais fácil conscientizar mais cooperados e poderem aos poucos libertarem um grande número de sujeitos do capitalismo que fazem dos mesmos verdadeiros escravos da economia social.

\section{REFERÊNCIAS BIBLIOGRÁFICAS}

ANDRIOLI, A. I. Trabalho Coletivo e Educação: um estudo das práticas cooperativas do Programa de Cooperativismo na Região da Fronteira Noroeste do Estado do Rio Grande do Sul. Unijuí/RS: UNIJUÍ, 2001.

FREIRE, P. Pedagogia do Oprimido. 06 ed. Rio de Janeiro: Paz e Terra, 1997.

FREIRE, P. Educação de Adultos, Hoje: algumas Reflexões. In: REIRE, Paulo. Política e Educação: ensaios. São Paulo: Cortez, 2001.

FREIRE, P. Educação como prática da liberdade. Rio de Janeiro: Paz e Terra, 2005.

GADOTTI, M. Escola Cidadã. 11. Ed. São Paulo: Cortez, 2006.

HOFFMANN, J. Avaliar para promover: As setas do caminho. $6^{\mathrm{a}}$ Ed. Porto Alegre: Mediação, 2004.

KRUPPA, S. M. P. Economia solidária e educação de jovens e adultos. Brasília: INEP, 2005.

LOPES, S. P.; SOUSA, L. S: EJA: Uma Educação Possível ou Mera Utopia? $\langle\underline{\text { http://www.cereja.org.br/pdf/revista_v/Revista SelvaPLopes.pdf }\rangle .}$. Acesso no dia 05/04/2013.

MOLL, J. Alfabetização de Adultos: desafios à razão e ao encantamento. Educação de Jovens e Adultos. Porto Alegre: Mediação, 2004.

MOURA, T. M. M. A prática pedagógica dos alfabetizadores de Jovens e Adultos: contribuições de Freire, Ferreiro e Vugotsky. Maceió: Edufal, 1999.

SINGER, P. Introdução a Economia Solidária. São Paulo, SP: Perseu Abramo, 2002.

SINGER, P. A. Economia Solidária como Ato Pedagógico. Economia Solidária e Educação de Jovens e Adultos. Brasília: INEP, 2005. 